\title{
Corrosion Behaviour of SMAW and GMAW Welded Mild Steel Attacked by Hydrochloride Acid
}

\author{
Muhamad Hellmy Hussin, NurAzida CheLah
}

\begin{abstract}
Corrosion is described as material's destruction or deterioration because of reaction with its surrounding environment. This type of degradation represents a tremendous economic loss since so much value of loss being described. Mostly, in petroleum industry, mild steel are still the most commonly used metal to build structures. However, acid which is hydrochloric acid has been used as acidizing operation since its advantage over other mineral acid. This may cause mild steel structure susceptible to corrosion. This project is about the study of the rate of corrosion on SMAW and GMAW welded mild steel with different time of exposure. The comparison of $f$ these two type of welded joint were subjected for microstructure analysis using SEM/EDX. Welded mild steel were prepared using SMAW and GMAW process with dimension of $100 \mathrm{~mm} \times 50 \mathrm{~mm} \times 6 \mathrm{~mm}$. Then, samples were inspected using NDT technique using magnetic particle testing. After that, the samples were immersed in $6 \mathrm{~mol}$ of $\mathrm{HCl}$ acid. Then, the corroded samples were cross-sectioned and were examined using SEM/EDX. The results show that, the rate of corrosion on SMAWwelded mild steel is higher compared to the GMAW welded mild steel. As the duration of exposure increase, the weight loss also increased as well as the value of the corrosion rate. This results were supported by the MPT showing that the flaws and defects on the SMAWwelded mild steel might be the cause that act as a stress raiser and thus, enhancing the corrosion degradation.
\end{abstract}

Index Terms: SMAW, GMAW, hydrochloric acid, weight loss, corrosion rate

\section{INTRODUCTION}

Corrosion is described as the metal's destruction or deterioration because of reaction with surrounding environment. Essentially, all environments are corrosive to some and certain degree. Some examples are air and moisture, rural atmospheres, urban atmospheres, industrial atmospheres, mineral acids, organic acids, alkalies and soils. In general, the inorganic materials are more corrosive than the organics. For example, corrosion in petroleum industry is due to sodium chloride, sulphur, hydrochloric and sulphuric acid and water than the oil, naphtha or gasoline [1-3]. Generally, many materials that display passivity effect are only negligibly affected by wide change in medium that has certain corrosive concentration. Many metals show similar

\section{Revised Manuscript Received on February 21, 2020.}

* Correspondence Author

Muhamad Hellmy Hussin*, Fabrication \& Joining, University of Kuala Lumpur Malaysia France Institute (UNIKL MFI), Selangor, Malaysia.

NurAzida CheLah, Fabrication \& Joining, University of Kuala Lumpur Malaysia France Institute (UNIKL MFI), Selangor, Malaysia.

(C) The Authors. Published by Blue Eyes Intelligence Engineering and Sciences Publication (BEIESP). This is an open access article under the CC BY-NC-ND license (http://creativecommons.org/licenses/by-nc-nd/4.0/) behaviour except at very high corrosive concentrations level,especially when the corrosion rate increases rapidly. For example, lead shows this effect, and it is believed to be due to the sulphuric acid and it is soluble in concentrated sulphuric acid.

Corrosion in crude oil refining units is a common problem worldwide and the most important issue is overhead corrosion. Due to the variation of process fluid and its chemical composition, the process parameter such as temperature, pressure, $\mathrm{pH}$ and moisture etc., the percentage of corrosive components is diverse in the refining process system. As a result, various corrosion problems will arise and that forces to adopt different types of preventive actions to minimize the corrosion affects. Respective chemical dosing, inhibitor dosing, water dosing, suitable desalting, using proper materials and maintaining appropriate operating process parameter in order to minimize the corrosion effects economically is also recommended in this paper.

Practically, as the concentration of corrosive medium increased, the corrosion rate is increased as well. Primarily, this is due to the fact that the amount of active species like hydrogen ions are increased as acid concentration is increased. Meanwhile, as acid concentration is increased further, the corrosion rate reaches a maximum and then decreases. It is undoubtedly due to the fact that at very high acid concentrations, the ionization is reduced. In addition, many of the common acids, such as sulphuric, acetic, hydrofluoric and others are virtually inert when in the pure state, or $100 \%$ concentration, and at moderate temperatures.

The steel for construction in petroleum industry for example, oil well, can range from mild steel, high corrosion resistant alloy and modified martensitic steel. However, carbon steel or mild steel is still the most commonly used materials for oil well, downhole tubulars, flow lines and transmission lines in the oil and gas industry. This is mainly because of its low costadvantage [4].

On the other hand, acid has been used as acidizing operation in the oil well in petroleum industry. One of the most common conventional acids is hydrochloric acid. It is because hydrochloric acid has primary advantage compared to other mineral acid in the acidizing operation, mainly because it is very soluble in the aqueous phase [5-8]. When hydrochloric acid used as acidizing treatments, the oil well structure is susceptible to the corrosion and subsequent degradation would occur on mild steel surface and its welded area. Although the weld joint of the structure coated, there would be certainty the coating of weld joint destructed or having flaws during coating. Gradually, this will affect the oil well reliability [7,9-12]. 
Moreover, corrosion of metals could be considered as extractive metallurgy in reverse. Most of the iron ores contain oxides of iron, and throughout deterioration,

Rusting of steel by water and oxygen results in hydrated iron oxide. In addition, rusting is a term reserved for steel and iron which having corrosion degradation.Although many others metals elements in its composition, it is still referred to steel compared to other oxides when corrosion occurs $[13,14]$.

It is indicated that the corrosion behaviour of carbon steel weldments constructed by fusion welding is reliant on many aspects. Corrosion of carbon steel weldments can caused by metallurgical outcomes for instance preferential corrosion of the HAZ or weld metal or it can be correlated with geometrical features such as stress concentration at the weld toe or creation of crevices cause by joint design. Furthermore, distinctive environmental states can stimulate localized corrosion condition [15-18]. Additionally, factors involved such as temperature, conductivity of the corrosive fluid or thickness of the liquid corrosive film in associate with the metal plays an important role in material's degradation [19-21]. Instead of that, in some cases, both metallurgical and geometric aspects will affect the metal properties [22-24]. Accordingly, the current paper presents the corrosion rate assessment of welded mild steel using different types of welding process which are SMAW and GMAW process in hydrochloric acid environment. The comparison of these two types of welded joint was subjected for microstructure analysis using SEM/EDX.

\section{MATERIALS AND METHODS}

\section{A. Material Preparation}

Material that been used in this work is mild steel or low carbon steel (LCS) since it is widely used in the petroleum industry to build oil well, pipelines, flow lines and etc. Mild steel is defined by the content of carbon(C) element which is less than $0.3 \%$. It is alloyed with magnesium $(\mathrm{Mg})$ and very small amount of Sulphur (S) to improve the hardenability and make the mild steel malleable and strong at high temperature. The composition analysis was carried out using Spectrometer Arc, modelSpectroMax testing machine for both base metal and filler electrode. The composition of LCS has been shown in Table 1.

Table 1 Element compositions in wt \% of mild steel

\begin{tabular}{|r|c|c|c|c|c|c|}
\hline $\mathbf{C}$ & $\mathbf{S i}$ & $\mathbf{S}$ & $\mathbf{C u}$ & $\mathbf{M n}$ & $\mathbf{P}$ & $\mathbf{F e}$ \\
\hline 0.25 & 0.28 & 0.05 & 0.2 & 1.03 & 0.04 & 98 \\
\hline
\end{tabular}

Table 2 Welding parameters used to performed welding process.

\begin{tabular}{|c|c|c|}
\hline \multirow{2}{*}{ Welding Parameter } & \multicolumn{2}{|c|}{ Description } \\
\cline { 2 - 3 } & SMAW & GMAW \\
\hline Type filler rod & E6013 & E70S-6 \\
\hline Amperage & $150 \mathrm{~A}$ & $128 \mathrm{~A}$ \\
\hline Voltage & $220 \mathrm{~V}$ & 214 \\
\hline
\end{tabular}

Table 3 Element compositions in wt\% of filler metal electrode

\begin{tabular}{|c|c|c|c|c|c|c|c|c|c|}
\hline & $\mathbf{C}$ & $\mathbf{S i}$ & $\mathbf{S}$ & $\mathbf{M n}$ & $\mathbf{P}$ & $\mathbf{N i}$ & $\mathbf{C r}$ & $\mathbf{M o}$ & $\mathbf{C u}$ \\
\hline E6013 & 0.065 & 0.337 & 0.015 & 0.485 & 0.013 & - & - & - & - \\
\hline E70S-6 & 0.15 & 0.80 & 0.035 & 1.40 & 0.025 & 0.15 & 0.15 & 0.15 & 0.5 \\
\hline
\end{tabular}

The mild steel plates were cut according to the size of $100 \mathrm{~mm} \times 50 \mathrm{~mm} \times 6 \mathrm{~mm}$ as shown in Fig. 1. Mild steel was marked to the dimension as shown in Table 1. Marking process was done by using permanent marker pen. Marking technique was used to optimize the usage of the plate thus minimizing the wastedplate. For this project, cutting process was performed by using band saw machine. After marking process, the part was cut out using band saw machines.

\section{B. Welding Parameters and Visual Inspection}

The welding process that been used in this project is shielded metal arc welding (SMAW) process because of its practicality and easy to operate. Type of electrode that been used is rutile type which is E6013. Table 2 and Table 3 show the specification of SMAW and GMAW machine and the chemical composition of electrode respectively.
Filler electrode E70S-6 usually used in all position low hydrogen iron powder electrode. It is normally used for welding variety of carbon and low alloy steels that require impact toughness at low temperatures. The selection of the welding filler electrode was based principally upon matching the mechanical properties and physical characteristics of the mild steel.

\section{Magnetic Particle Testing (MPT)}

After welding, the specimen will undergo magnetic particle inspection testing (MPT). The purpose of this inspection is to detect any flaws or defects in surface or sub surface of the specimens. Before the inspection conducted the specimens will be cleaned with acetone. 
It is an important procedure in order to prevent the sample from any kinds of dirt, scale, loose rust, weld spatter, grease, oil and any foreign matter that may affect the test sensitivity. Flaws or defects detected will be recognized and recorded. Fig. 1 shows the illustration of weld joint section subjected to MPT.

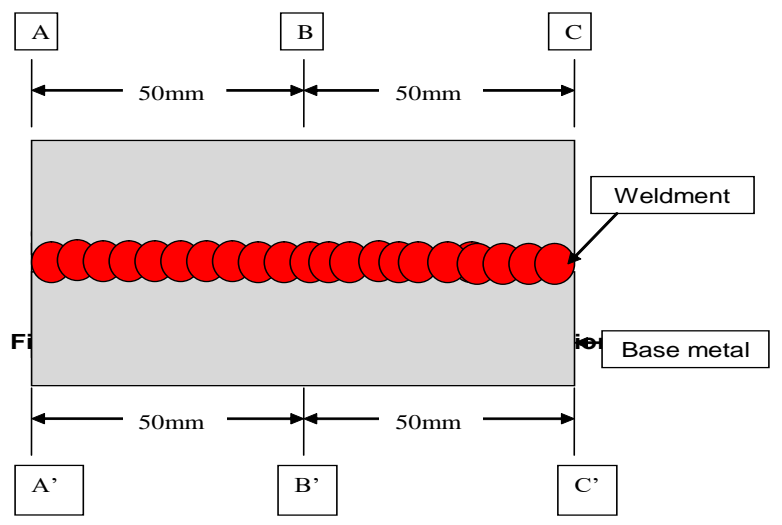

Fig. 1 Welded joint orientation

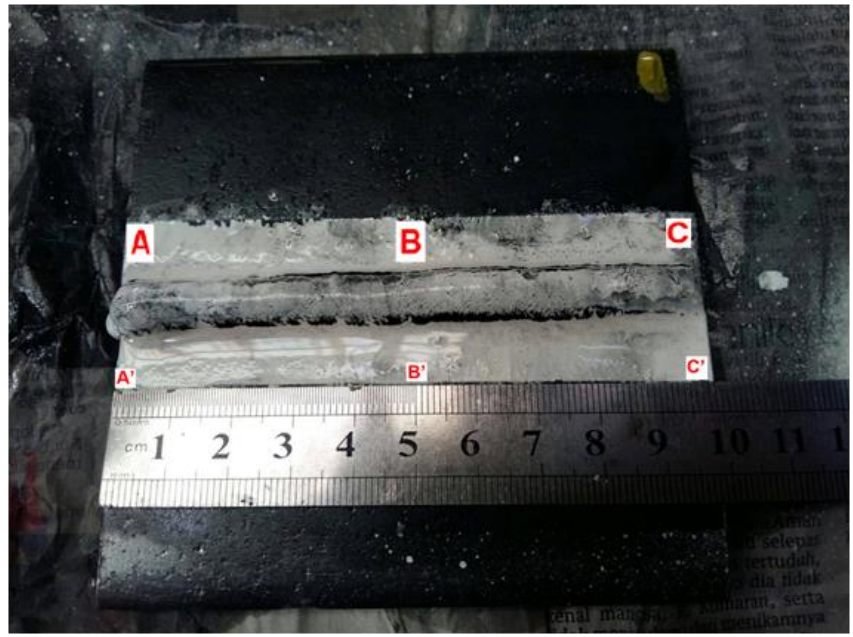

Fig. 2 Welded joint plate after undergone MPT

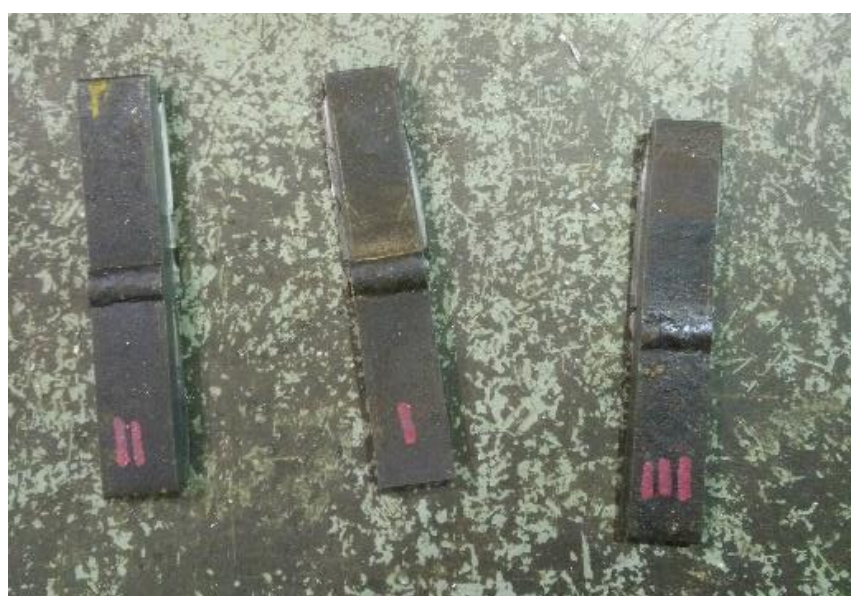

Fig. 3 Corrosion coupon

\section{Spectrometer Arc Test}

In order to determine the type of base metal specimen used in this study, the base metal specimen was cut and tested by using Spectrometer Arc, modelSpectroMax testing machine. Moreover, the test was performed to obtain and confirmed the composition of the mild steel base metal used.

\section{E. Weight Measurement}

The weight measurement is used to measure the weight of the test specimens before and after immersion test in hydrochloric acid ( $\mathrm{HCl})$ solution. The initial and final weight of the test specimens was measured by using microbalance to get the precise measurement of the specimen's weight.

\section{F. Immersion Testing}

The main purpose of immersion testing is to evaluate the corrosion rate of the specimens. Data obtained from weight loss measurement were used to determine the corrosion rate for each specimen. The specimens were exposed to three different level of exposure timein $6 \mathrm{~mol}$ concentration. The 6 mol of concentration was choosing to relate the real corrosive media as in the oil well which is about $5 \%$ to $28 \%$ of concentration.

The specimens will immerse in $6 \mathrm{~mol}$ of hydrochloric acid with different exposure timethat is $60 \mathrm{~min}, 120 \mathrm{~min}$ and $180 \mathrm{~min}$. The acid was filled in the glass beaker. Accordingly, the leaching procedure was conducted at an L/S ratio of 10:1 with $6 \mathrm{~mol} / \mathrm{L}$ hydrochloric acid.

\section{G. Corrosion Rate Measurement}

The corrosion rate expressed in weight loss is meaningful for evaluation in the situations where the metal surface corrodes uniformly across the exposed area.

To calculate the corrosion rate:

Corrosion rate $(\mathrm{C} . \mathrm{R})=(\mathrm{K} \times \mathrm{W} / \mathrm{A} \times \mathrm{D} \times \mathrm{T})$

Where;

$\mathrm{T}=$ time of exposure of the metal sample in hours

$\mathrm{A}=$ area of sample in $\mathrm{cm} 2$

$\mathrm{W}=$ weight loss in milligrams

$\mathrm{D}=$ metal density in $\mathrm{g} / \mathrm{cm} 3$

$\mathrm{K}=\mathrm{a}$ constant

Where;

$\mathrm{K}=$ Millimetre per year $(\mathrm{mm} / \mathrm{y})=8.76 \mathrm{x}$

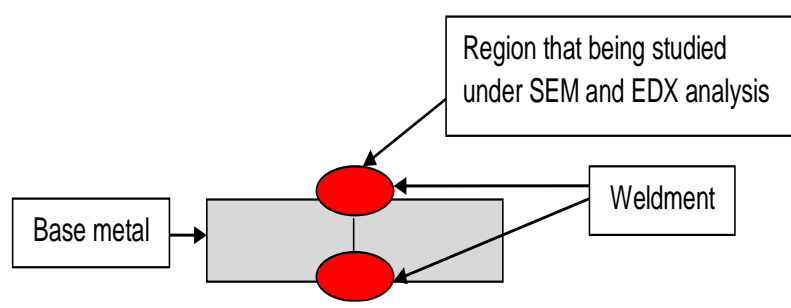

Fig. 4 Test specimen illustration

\section{H. SEM/EDX Analysis}

The dimension of the specimen for this test is $(10 \mathrm{~mm} \mathrm{x}$ $30 \mathrm{~mm} \times 6 \mathrm{~mm}$ ). The purpose of conducting SEM is to obtain and determine the oxide film at the surface of corroded weld bead. For EDX analysis, it is an analytical technique used for the elemental or chemical characterization of the specimen sample. Both samples were then characterized using a scanning electron microscope (SEM) LEO 1450 model equipped with an energy dispersive X-ray (EDX) to obtain cross sectional images of the joint between base metal and welded part. Fig. 4 shows the specific region for metallographic and elemental composition analysis. 


\section{RESULTS AND DISCUSSION}

\section{A. Defects Analysis and Corrosion Rate}

The flaws and defects detected from the testing was observed and recorded in Table 4 and 5.

Table 4 Summary of MPT result of mild steel welded joint using SMAW process

\begin{tabular}{|l|l|l|}
\hline No & Result & Remark \\
\hline 1 & acceptable & No significant discontinuity \\
\hline 2 & acceptable & No significant discontinuity \\
\hline 3 & acceptable & No significant discontinuity \\
\hline
\end{tabular}

Table 5 Summary of MPT result of mild steel welded joint using GMAW process

\begin{tabular}{|l|l|l|}
\hline No & Result & Remark \\
\hline 1 & acceptable & $\begin{array}{l}\text { No significant } \\
\text { discontinuity }\end{array}$ \\
\hline 2 & acceptable & $\begin{array}{l}\text { No significant } \\
\text { discontinuity }\end{array}$ \\
\hline 3 & acceptable & $\begin{array}{l}\text {-crater pipe. Accept } \\
\text { because do not } \\
\text { exceed the } \\
\text { acceptance criteria. }\end{array}$ \\
\hline
\end{tabular}

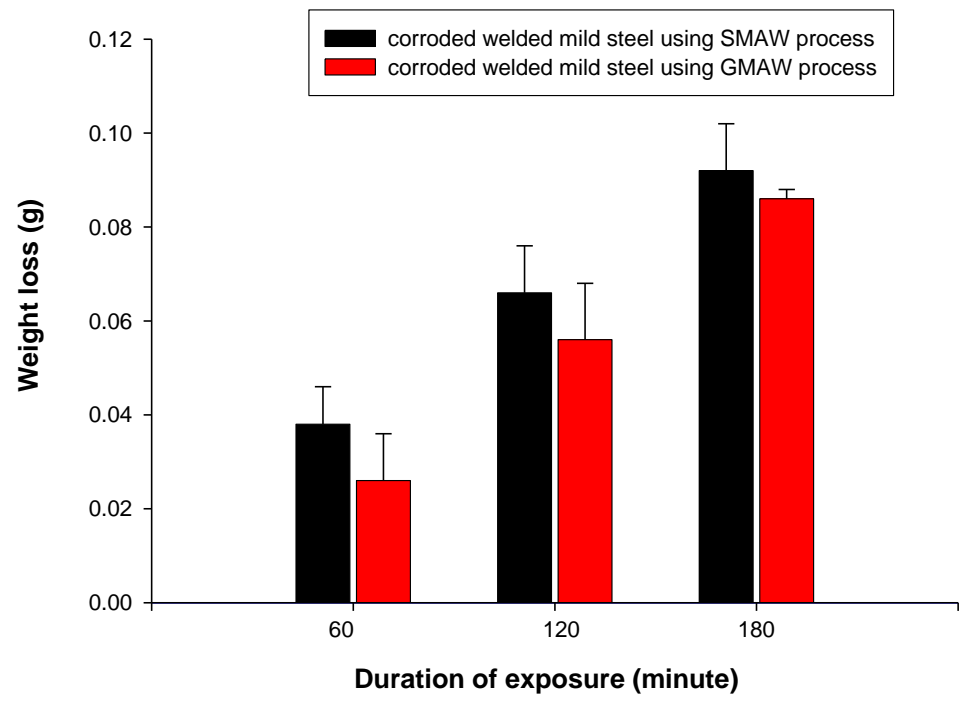

Fig. 5 Weight loss of corroded welded mild steel using SMAW and GMAW process

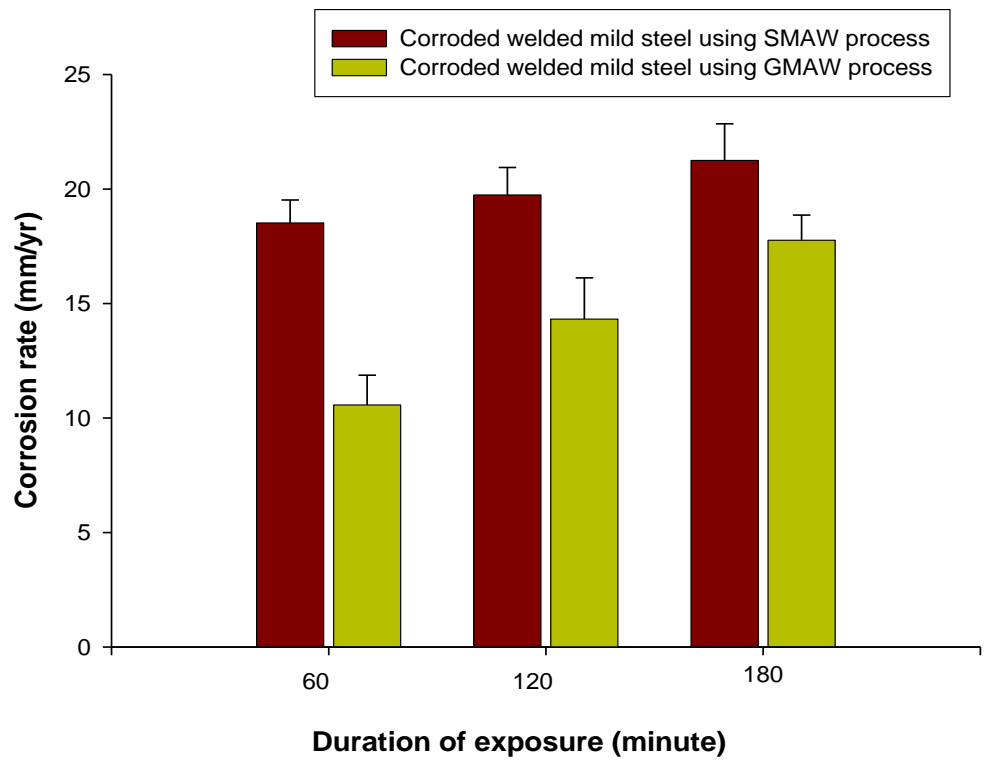

Fig. 6 Corrosion rate of corroded welded mild steel using SMAW and GMAW process

According to Figs.5 and 6, it is shows that the rate of corrosion of test specimen for $60 \mathrm{~min}$ of exposure to hydrochloric acid is $39.05 \mathrm{~mm} /$ year. When the time of exposure increase from $60 \mathrm{~min}$ to $120 \mathrm{~min}$ of exposure to hydrochloric acid, the rate of corrosion is decreases to 31.16

$\mathrm{mm} /$ year. The rate of corrosion decreases again to 30.24 $\mathrm{mm}$ /year when time of exposure increase to $180 \mathrm{~min}$ of exposure in hydrochloric acid. The decreasing in rate of corrosion means it provides 

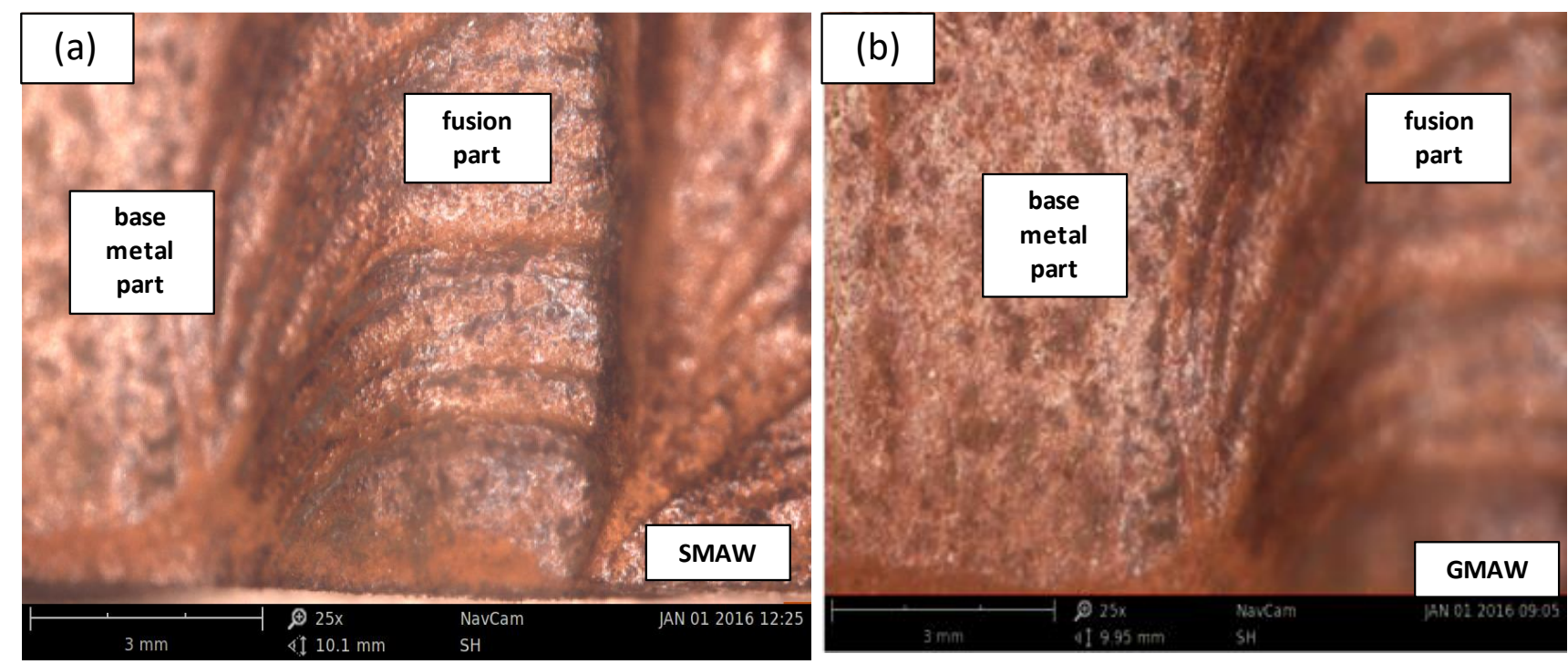

Fig.7 Corroded welded mild steel of different type of welding process (a) SMAW, and (b) GMAW
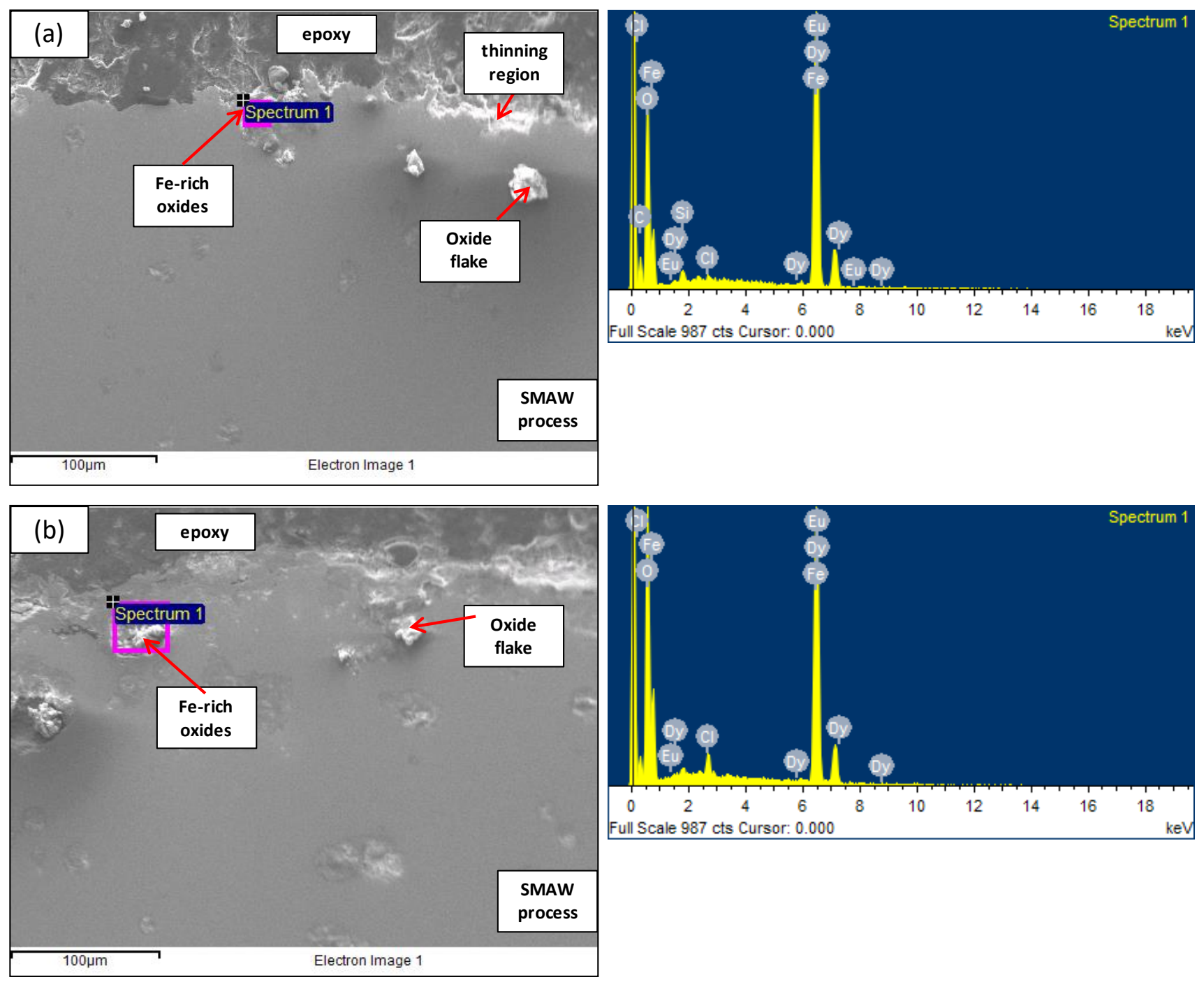

Fig. 8 SEM and EDX analysis of welded mild steel using,(a) SMAW and (b) GMAW process.

Retrieval Number: B2861129219/2020@BEIESP DOI: 10.35940/ijeat.B2861.029320 Journal Website: www.ijeat.org

\section{Published By:}

671 Blue Eyes Intelligence Engineering \& Sciences Publication

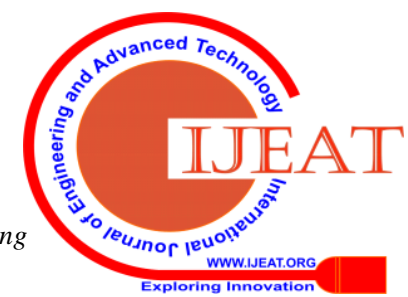


an oxide layer which act as protective barrier at specimens surface.

\section{B. Metallographic and Composition Analysis of Corroded Samples}

Exposing a base metal part of mild steel to HCL acid environments results in growth of an oxide scale as shown in Fig. 7. Fig. 8 shows a micrograph of SEM image and EDX spectrums of corroded mild steel base metal.Fig. 8shows the sample which is also been exposed to the hydrochloric acid solution for 60 min time of exposure. From the image shown, there are black area which is the epoxy material used to mounted the sample for SEM and EDX analysis. There are also micro-flakes depicting the surface damage due to corrosion of hydrochloric acid. Lastly, there is weld metal that are not damage from corrosion. From Fig.8, EDX analysis shows that the $\mathrm{Cl}$ peaks in the above spectra clearly indicate the reaction of metal with $\mathrm{HCl}$. As the samplecorroding more in $\mathrm{HCl}$ solution the sharp peaks of chloride ions appears in the spectra. Hence, it can be revealed that the results are in good agreement with the results suggested by the weight loss showing that sample welded using SMAW shows the highest corrosion behaviour compared to GMAW sample.

Fig. 8(a) shows a selected of SEM micrograph at higher magnification, presents an accumulation of black corrosion residue at point 1 , after exposing to HCL environment. Black oxide crystals have been identified by EDX spectrum in Fig. 8 (b) shows that the spectrum peak 1 in SEM image contained strong two peaks, which were assigned to $\mathrm{Fe}$ and $\mathrm{O}$. As expected, the peaks around 0.8 and $6.3 \mathrm{keV}$ are related to the binding energies of $\mathrm{Fe}$. The peak of $\mathrm{O}$ shows the existence of oxide compounds on the surface of the sample and the possible related oxide compound is Fe-rich oxides. Meanwhile, the bright and smooth areas also show the presence of strong $\mathrm{Fe}$ and $\mathrm{O}$ peaks. It is confirmed that the sign of $\mathrm{Cl}$ peak shows the possible influence of chloride ions on the sample especially in Fig. 8 (b) showing the effects of $\mathrm{Cl}$ ions on SMAW welded joint that was more prominent compared to GMAW welded joints. The potential of iron in chloride solution is due to the dissolution of the mild steel surface by the aggressive chloride ions attack.

\section{CONCLUSION}

From the investigation, the rate of corrosion of welded mild steel at 180 minutes time of exposure is lower than the rate of corrosion of welded mild steel at 60 minutes time of exposure. It can be concluded, the longer the time of exposure, the lower the rate of corrosion mainly for SMAW sample compared to GMAW sample. Non destructive testing has been performed on the welded mild steel before immersion test. From magnetic particle testing, flaws and defects on the surface and sub surface can be detected. Any unacceptable flaws and defects on the weld mild steel, has been rejected. Based on the microstructural analysis, it shows clearly surface damage on the welded mild steel mostly on SMAW sample compared to GMAW sample due to corrosion from hydrochloric acid solution.

\section{REFERENCES}

1. Afoegba, S. C. (2018). An investigation to improve the mechanical properties of A36 weldment. Pyrex Journal of Engineering and Manufacturing Technology, 3(1), 1-9.

2. Arivazhagan, N., Narayanan, S., Singh, S., Prakash, S., \& Reddy, G. M. (2012). High temperature corrosion studies on friction welded low alloy steel and stainless steel in air and molten salt environment at 650 degrees C. Materials \& Design, 34, 459-468.

3. Asibeluo, I. S., \&Emifoniye, E. (2015). Effect of arc welding current on the mechanical properties of A36 carbon weld joints. SSRG International Journal of Mechanical Engineering (SSRG-IJME), 2(9), 29-37.

4. Basabe, V. V, \&ASzpunar, J. A. (2004). Growth rate and phase composition of oxide scales during hot rolling of low carbon steel. ISIJ International, 44(9), 1554-1559.

5. Bhattacharya, D. K. (1997). Failures of welded joint. Proceedings COFA, 212-220.

6. Budiarto, Turnip, K., \&Hantariksa. (2018). The effect of current gouging arc welding analysis of A283 Gr C steel to the tensile strength, hardness and microstructure. 2nd Nommensen International Conference on Technology and Engineering, 420, 1-8.

7. Devletian, J. H., \& Heine, R. W. (1974). Effect of Boron content on carbon steel welds. Welding Research Supplement, (198), 45-53.

8. Finsgar, M., \& Jackson, J. (2014). Application of corrosion inhibitors for steels in acidic media for the oil and gas industry: A review. Corrosion Science, 86, 17-41.

9. Garcia, M. P., Mantovani, G. L., Kumar, R. V, \&Antunes, A. (2017) Corrosion behavior of metal active gas welded joints of a high-strength steel for automotive application. Journal of Materials Engineering and Performance, 1-15.

10. Karlsson, L., Keehan, E., Andren, H. O., \&Bhadeshia, H. K. D. H. (2004). Development of high strength steel weld metals - Potential of novel high-Ni compositions. Eurojoin, 5, 1-8.

11. Kiaei, M., Mahdavi, S., Kialashaki, A., Nemati, M., Samariha, A., \&Saghafi, A. (2014). Chemical composition and morphological properties of canola plant and its potential application in pulp and paper industry. Cellulose Chemistry and Technology, 48(1), 105-110.

12. Kursun, T. (2011). Effect of the GMAW and the GMAW-P welding processes on microstructure, hardness, tensile and impact strength of AISI 1030 steel, joints fabricated by ASP316L austenitic stainless steel filler metal. Archives of Metallurgy And Materials, 56(4), 956-963.

13. Melchers, R. E. (2018). A review of trends for corrosio loss and pit depth in longer-term exposures. Corrosion and Materials Degradation, $1,42-58$.

14. NurAzida, C. L., \& Muhamad Hellmy, H. (2017). Proposed oxidation mechanisms of welded $6061 \mathrm{Al}$ alloy using ER 5356 (Al-Mg) filler metal oxidized at 6000C. International Journal of Applied Engineering Research, 12(24), 14568-14573.

15. Oh, S. J., Cook, D. C., \& Townsend, H. E. (1998). Characterization of iron oxides commonly formed as corrosion products on steel. Hyperfine Interactions, 112, 59-65.

16. Othman, N. K., Bakar, S. R. S., Jalar, A., Syarif, J., \& Ahmad, M. Y. (2011). The effect of filler metals on mechanical properties of $6 \mathrm{~mm}$ AA 6061-T6 welded joints. Materials Processing Technologies, Pts 1 and 2, 873-876.

17. Prasad, K., Bazaka, O., Chua, M., Rochford, M., Fedrick, L., Spoor, J. ...Bazaka, K. (n.d.). Metallic biomaterials: Current challenges and opportunities. Materials, 10(884), 1-33.

18. Talabi, S. I., Owolabi, O. B., Adebisi, J. A., \&Yahaya, T. (2014). Effect of welding variables on mechanical properties of low carbon stee wekded joint. Advances in Production Engineering \& Management, 9(4), 181-186.

19. Uzun, F., \& Bilge, A. N. (2017). The effect of caron content and submerged ard welding process on hardness of carbon steels. Journal for Foundations and Applications of Physics, 4(1), 1-8.

20. Wang, S., Liu, D., Du, N., Zhao, Q., Liu, S., \& Xiao, J. (2015) Relationship between dissolved oxygen and corrosion characterization of X80 steel in acidic soil simulated solution . International Journal of Electrochemical Science, 10, 4393-4404.

21. Young, D. J., \& Zhang, J. (2013). Carbon corrosion of alloys at high temperature. The Journal of The Southern African Institute of Mining and Metallurgy, 113, 149-.

22. Abuluwefa, H. T. (2012). Kinetics of high temperature oxidation of high carbon steels in multi-component gases approximating industrial steel reheat furnace atmospheres. Proceedings of the International MultiConference of Engineers and Computer Scientist (IMECS 2012), $1-5$. Hong Kong. 
23. Birosca, S., West, G. D., \& Higginson, R. L. (2005). Microstructural investigation of the oxide scale on low carbon steel. Metal, 1-8.

24. Britt, J. (2011). All about Iron. Techno File, 14-15.

\section{AUTHORS PROFILE}

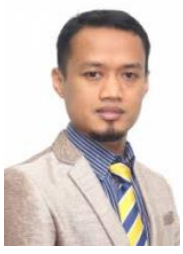

Muhamad Hellmy Hussin, is a lecturer in University of Kuala Lumpur Malaysia France Institute (UNIKL MFI) located at Bandar BaruBangi, Selangor for fourteen years. His expertise is in Innovation and Engineering Design, and also in Corrosion and Failure Analysis. He did his Bac. (Hons.) in Industrial Production Management at the University Nice Sophie Antipolis (UNSA), France, and then pursued his Master Degree in Innovation and Engineering Design at University of Putra Malaysia (UPM) Serdang, Selangor.Over the last eight years he becomes involved in welding and joining research works. And since then he has continued his research and involved in Corrosion and Failure Analysis research areas, Corrosion and failure analysis works. Now, he pursue his PhD in (Mechanical), focusing on High Temperature Corrosion in Hot Gases Environment. He has published articles and journals mainly in Welding and Joining, Corrosion degradation and Failure Analysis research works.

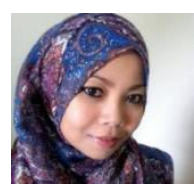

Dr. NurAzida CheLah, is a senior lecturer on Corrosion degradation and Failure Analysis studies at the University of Kuala Lumpur Malaysia France Institute (UNIKL MFI), Bandar BaruBangi, Selangor. She did her Bac (Hons) in Materials Science and then pursued her Master degree in Mechanical Engineering majoring in Fatigue failure Assessment on welded joint at University of Putra Malaysia (UPM) Serdang, Selangor. Her PhD focusing on High Temperature Corrosion Study on Aluminium Welded Joint at The National University of Malaysia (UKM), Bangi, Selangor. And since 2007 she started writing an articles and journals mostly on Fatigue Assessment Analysis, Welding and Joining, Corrosion degradation and Failure Analysis Studies. 